\title{
A questionnaire based study to evaluate the knowledge, attitude and perception towards pharmacovigilance among doctors in rural hospital, Jammu, India
}

\author{
Shallini Gupta $^{1 *}$, Kanika Khajuria ${ }^{1}$, Vijay Khajuria ${ }^{1}$, Niraj Kumar ${ }^{2}$
}

\begin{abstract}
${ }^{1}$ Department of Pharmacology, Government Medical College, Jammu, Jammu and Kashmir, India

${ }^{2}$ Department of Pediatrics, Sub district Hospital, Akhnoor, Jammu. Jammu and Kashmir, India
\end{abstract}

Received: 11 September 2018 Accepted: 05 Octoberr 2018

\section{*Correspondence to: \\ Dr. Shallini Gupta, \\ Email: shallinirajkdr@ gmail.com}

Copyright: (c) the author(s), publisher and licensee Medip Academy. This is an openaccess article distributed under the terms of the Creative Commons Attribution NonCommercial License, which permits unrestricted noncommercial use, distribution, and reproduction in any medium, provided the original work is properly cited.

\begin{abstract}
Background: Monitoring and reporting of adverse drug reactions (ADRs) is very important to minimize or prevent drug caused harm. Thus, pharmacovigilance deals with it and ensures the patient safety. However, most of pharmacovigilance centers are concentrated in the urban tertiary care hospitals and contributes the maximum reports of ADRs. Participation of the rural health workers is equally important towards the success of pharmacovigilance.

Methods: The study was conducted using a pre-validated questionnaire among forty doctors in rural Sub district hospital Akhnoor, Jammu after approval of the institutional ethical committee of Government Medical Jammu. The questionnaire consisted of 16 questions ( 7 related to knowledge, 4 related to attitude, and 4 related to practice and one question pertained to under reporting). The responses were recorded, and data obtained was analysed and presented as number and percentage.

Results: Total $66.6 \%$ doctors gave correct response regarding the definition of pharmacovigilance and purpose of pharmacovigilance was given by $76.6 \%$ of doctors. $70 \%$ agreed that ADR reporting is a professional obligation for them. $80 \%$ responded that health care professionals are responsible for reporting ADRs. $63.3 \%$ of them were aware of a pharmacovigilance programme of India. A total of $96.6 \%$ doctors agreed that reporting of ADR is necessary and $93.3 \%$ were of the view that pharmacovigilance should be taught in detail. Majority of doctors have experienced ADRs in patients and 36.6\% have seen the ADR reporting form. However, only $10 \%$ have ever reported ADR to a pharmacovigilance center. No remuneration $(50 \%)$, lack of time to report ADR $(30 \%)$, belief that a single unreported case may not affect ADR database (10\%), and difficulty to decide whether ADR has occurred or not (10\%) were important causes for under reporting of ADRs.

Conclusions: Current study has shown that majority of the doctors have good knowledge and attitude about pharmacovigilance. However, under reporting is still a major concern among rural doctors and efforts are needed to address this problem of under reporting by conducting CMEs on regular basis.
\end{abstract}

Keywords: ADRs, Attitude, Knowledge, Practice, Pharmacovigilance

\section{INTRODUCTION}

Adverse drug reactions (ADRs) are the major hazards associated with the use of drugs. World Health Organization (WHO) has defined adverse Drug Reaction (ADR) as any noxious, unintended and undesired effect of a drug which occurs at doses used in humans for prophylaxis, diagnosis or therapy of disease or for the modification of physiological function. ${ }^{1}$ ADRs are of different types. The two of the most common include type A: augmented (dose related effects) and type B: bizarre (abnormal interaction between patient and drug). Other 
types - type C (chronic effects), type D (delayed effects), type $\mathrm{E}$ (end of treatment effects). ADRs can also be categorized on the basis of onset of an event as

- Acute

- Sub-acute

- Latent or on the basis of severity of reaction as:

- Mild,

- Moderate

- Severe. $^{2}$

ADRs are responsible for morbidity, mortality and remarkable increase in hospital admissions which ranges from $0.3 \%$ to $11 \% .^{3-5}$ So it is imperative to identify and cure ADRs as early as possible since most of these are reversible and preventable. Monitoring and reporting of ADRs is very important in identifying the adverse reaction trends and to minimize or avert harm to patients arising from the drugs. ${ }^{6}$

Pharmacovigilance deals with the detection, reporting and monitoring of these adverse event and is defined as the science and activities relating to the detection, assessment, understanding and prevention of adverse effects or any other possible drug-related problem, particularly long term and short-term adverse effects of medicines. ${ }^{7}$

Most countries have their own pharmacovigilance programmes due to the diversity in drug response, prescribing habits, drug regulatory system and availability of drugs etc. ${ }^{8}$ India has its own PvPI (pharmacovigilance programme of India).

One major concern about pharmacovigilance is the underreporting of ADRs which may be due to inadequate funds, less number of trained staff and lack of awareness about detection, communication and spontaneous monitoring of ADRs. ${ }^{9,10}$

The success of pharmacovigilance programme depends on participation of health care professionals including doctors, paramedical staff from all the sectors be it urban or rural. In our country majority of ADR reporting centers are located in tertiary care hospitals with well-established reporting mechanism and most of the reports originate from these centers. ${ }^{11,12}$

The participation of rural health professional in pharmacovigilance is equally important, so to assess their understanding and knowledge of ADR reporting or pharmacovigilance the present questionnaire-based study was conducted.

\section{METHODS}

The study was carried out using a pre-validated survey questionnaire among the doctors in rural sub district hospital Akhnoor in Jammu. This study was approved by the institutional Ethical Committee of Government Medical Jammu, vide no. I4C/2018/532.

\section{Inclusion criteria}

- All the doctors whether graduates and post graduates

- Those who consented to participate in the study.

\section{Exclusion criteria}

- Those who did not consent

- All the paramedical staff including nurses, lab technicians.

The questionnaire was adapted from the previously published paper and modified according to the need of the present study. ${ }^{13}$ The study objectives were briefed to the participants and their informed consent was obtained.

The confidentiality of their response was maintained. Overall, there were 16 questions ( 7 related to knowledge, 4 related to attitude, and 4 related to practice and one question pertained to underreporting. These questions were designed based on earlier studies for assessing KAP of ADR reporting. ${ }^{13,14}$ Responses correct, and wrong answers were recorded.

\section{Statistical analysis}

The data obtained was analysed and presented as number and percentage in table form.

\section{RESULTS}

Total of 30 doctors including both graduate and post graduates participated in the study and questionnaires were distributed among them. The correct answers were recorded.

\section{Knowledge}

Correct definition of pharmacovigilance was given by $66.6 \%$ of doctors. $76.6 \%$ were aware that the most important purpose of pharmacovigilance is to identify safety of the drug. $70 \%$ of them agreed that ADR reporting is a professional obligation for them. $63.3 \%$ of them were aware regarding the existence of a pharmacovigilance programme of India and $56.6 \%$ knew that the regulatory body responsible for monitoring ADRs in India is Central Drugs Standard Control Organization (CDSCO). International center for ADR monitoring located in Sweden was known by $53.3 \%$ of doctors (Table 1 ).

\section{Attitude}

A total of $96.6 \%$ doctors agreed that reporting of ADR is necessary. $93.3 \%$ were of the view that pharmacovigilance should be taught in detail to healthcare professional.

Only $46.6 \%$ have read articles on prevention of ADRs. $60 \%$ wanted that ADR monitoring center should be established in every hospital (Table 2). 


\section{Practice}

Among the participants, 53.3\% have experienced ADRs in patients and $36.6 \%$ have seen the ADR reporting form. Only $10 \%$ of them have ever reported ADR to pharmacovigilance center. None of them have ever been trained on reporting ADRs (Table 3).

\section{Reasons for under-reporting}

The factors discouraging participants from reporting ADRs were no remuneration $(50 \%)$, lack of time to report ADR $(30 \%)$, belief that a single unreported case may not affect ADR database (10\%), and difficulty to decide whether ADR has occurred or not (10\%) (Table 4).

Table 1: Knowledge related responses.

\begin{tabular}{|lllll|}
\hline Questions asked & \multicolumn{2}{c|}{ Correct response } & \multicolumn{2}{l|}{ Incorrect response } \\
\hline Define pharmacovigilance & Number & $\boldsymbol{\%}$ & Number & $\boldsymbol{\%}$ \\
\hline Important purpose of pharmacovigilance & 20 & 66.6 & 10 & 33.3 \\
\hline Do you think ADR reporting is a professional obligation & 23 & 76.6 & 7 & 23.3 \\
\hline Health care professionals are responsible for reporting ADRs & 21 & 70 & 9 & 30 \\
\hline $\begin{array}{l}\text { Do you know regarding existence of pharmacovigilance programme of } \\
\text { India }\end{array}$ & 24 & 80 & 6 & 20 \\
\hline In India regulatory body responsible for monitoring ADRs & 19 & 63.3 & 11 & 36.6 \\
\hline International center for ADR monitoring & 17 & 56.6 & 13 & 43.3 \\
\hline
\end{tabular}

Table 2: Attitude related responses.

\begin{tabular}{|lllll|}
\hline Questions asked & \multicolumn{2}{c|}{ Correct response } & \multicolumn{2}{l|}{ Incorrect response } \\
\hline Do you think ADR reporting is necessary & Number & \% & Number & \% \\
\hline $\begin{array}{l}\text { DO you think pharmacovigilance should be taught in detail to health care } \\
\text { professional }\end{array}$ & 29 & 96.6 & 1 & 3.33 \\
\hline Have you read any article on prevention of ADR & 28 & 93.3 & 2 & 6.66 \\
\hline Opinion about establishing ADR monitoring centre in every hospital & 14 & 46.6 & 16 & 53.3 \\
\hline
\end{tabular}

Table 3: Practice related responses.

\begin{tabular}{|llll|}
\hline $\begin{array}{l}\text { Have you ever experienced } \\
\text { ADR in your patient in your } \\
\text { professional practice }\end{array}$ & $\begin{array}{l}\text { Have you ever reported } \\
\text { ADR to the } \\
\text { pharmacovigilance center }\end{array}$ & $\begin{array}{l}\text { Have you ever seen ADR } \\
\text { reporting form }\end{array}$ & $\begin{array}{l}\text { Have you been } \\
\text { trained how to report } \\
\text { ADR }\end{array}$ \\
\hline Yes N $(\%)$ & Yes N $(\%)$ & Yes N $(\%)$ & No N $(\%)$ \\
\hline $10(33.3 \%)$ & $3(10 \%)$ & $11(36.6 \%)$ & $0(100 \%)$ \\
\hline
\end{tabular}

Table 4: Reasons for underreporting.

\begin{tabular}{|llll|}
\hline No remuneration & $\begin{array}{l}\text { Lack of time to report } \\
\text { ADR }\end{array}$ & $\begin{array}{l}\text { Single unreported case may have no } \\
\text { effect on ADR database }\end{array}$ & $\begin{array}{l}\text { Difficulty to decide whether } \\
\text { ADR has occurred or not }\end{array}$ \\
\hline $\mathbf{N}(\boldsymbol{\%})$ & $\mathbf{N}(\boldsymbol{\%})$ & $\mathbf{N}(\boldsymbol{\%})$ & $\mathbf{N}(\%)$ \\
\hline $15(50 \%)$ & $9(30 \%)$ & $3(10 \%)$ & $3(10 \%)$ \\
\hline
\end{tabular}

\section{DISCUSSION}

Drugs though are administered for their beneficial effects, but they may also cause harmful effects in some individuals known as adverse drug reactions. These ADRs are important cause of morbidity and mortality and in addition increase health care costs. ${ }^{3}$
Spontaneous reporting of ADRs plays important role in the detecting serious and unusual ADRs to ensure drug safety and has resulted in the withdrawal of certain drugs like rofecoxib, cisapride, terfenadine, etc. It is of utmost importance to recognise them early, analyse, report and prevent them because at many of them are revocable and preventable. 
Pharmacovigilance concerns with identifying and minimizing these harmful effects and in our country PvPI (pharmacovigilance programme of India) oversees it and contributes to the World Health Organization (WHO) Uppsala Monitoring Centre. PvPI recommends that all ADRs should be reported whether serious, non-serious, unusual or new. PvPI has made a great effort in making health care workers aware of pharmacovigilance and this has resulted in sea change in their knowledge, attitude and practice towards this programme. However, still under reporting remains a serious issue.

Number of reports have poured in recent past regarding ADRs, but a few of them are from rural area. So, the present study was undertaken to understand the issues relating to pharmacovigilance among doctors working in rural hospital.

Current study revealed that doctors in the rural set up have good knowledge, attitude regarding pharmacovigilance and $70 \%$ agreed that $\mathrm{ADR}$ reporting is a professional obligation, Majority of doctors agreed that reporting of ADR is necessary and felt that ADR monitoring center should be established in every hospital.

Most of studies in past have also shown similar findings in demonstrating good knowledge among doctors. ${ }^{15,16}$ However contrary to our results a few studies recorded low knowledge, awareness, and practice of pharmacovigilance among rural doctors. ${ }^{17}$

However, in current study it was observed that less number of the participants had experienced ADRs and seen the ADR reporting form. Only $10 \%$ have ever reported ADR to pharmacovigilance center and this underscores the importance of continuous updating health professionals regarding pharmacovigilance programme to overcome under reporting

Reasons for under reporting in present trial were lack of incentives, lack of time to report, belief that a single report is going to make difference and difficulty to diagnose ADR. These findings suggest that despite adequate knowledge regarding pharmacovigilance they lacked in reporting the ADRs. Number of previous studies have also recorded similar observations in the past. ${ }^{18,19}$

Tendon VR et al, has shown the lack of knowledge and awareness about pharmacovigilance programme of India (PvPI), and reported lethargy, indifference, insecurity, complacency, workload, lack of training were the common factors responsible for under reporting. ${ }^{20}$

The current study has limitation of having small number of participants and single hospital based. Only doctor was assessed, while other health care workers like pharmacists, nurses who can make a major difference to the ADR reporting were not involved.

\section{CONCLUSION}

Current study has shown that majority of the doctors have good knowledge and attitude about pharmacovigilance. However, under reporting is still a concern. As there is constant inflow of newer medicines in the Indian market that increases the probability of more ADRs and this scenario further enhance importance of pharmacovigilance. Therefore, serious effort is advocated to redress the problem of under reporting.

Funding: No funding sources

Conflict of interest: None declared

Ethical approval: The study was approved by the Institutional Ethics Committee of Government Medical Jammu, India (vide no. I4C/2018/532)

\section{REFERENCES}

1. World Health Organization. International drug monitoring: the role of national centres. Report of a WHO meeting. World Health Organ Tech Rep Ser. 1972;498:1-25.

2. Kessler DA, Natanblut S, Kennedy D, Lazar E, Rheinstein P, Anello C, et al. Introducing MEDWatch: a new approach to reporting medication and device adverse effects and product problems. JAMA. 1993 Jun 2;269(21):2765-8.

3. Lee A, Thomas SHL. Adverse drug reactions. In: Walker R., Edward C, eds. Clinical Pharmacy and Therapeutics. 3rd ed. Churchill Livingstone; 2003:3346.

4. Classen DC, Pestotnik SL, Evans RS, Lloyd JF, Burke JP. Adverse drug events in hospitalized patients: excess length of stay, extra costs, and attributable mortality. JAMA. 1997 Jan 22;277(4):301-6.

5. WHO. The importance of pharmacovigilance. World Health Organization, Geneva. 2002:146-157.

6. Phatak A, Nagari BG. Safety of medicines. Pharm Times. 2003;35:19-21.

7. Olsson S. The need for pharmacovigilance. In: Gupta SK. Pharmacology and Therapeutics in the New Millennium. New Delhi: Narosa Publishing House; 2001:502-508.

8. Oshikoya KA, Awobusuyi JO. Perceptions of doctors to adverse drug reaction reporting in a teaching hospital in Lagos, Nigeria. BMC Clin Pharmacol. 2009 Dec;9(1):14.

9. Hazell L, Shakir SA. Under-reporting of adverse drug reactions. Drug Safety. 2006 May 1;29(5):385-96.

10. Moride Y, Haramburu F, Requejo AA, Begaud B. Under-reporting of adverse drug reactions in general practice. Br J Clin Pharmacol. 1997 Feb;43(2):177-81.

11. Kulmi M, Reddy P, Dhakre S, Shinde M, Goyal C. Knowledge, attitude and practices of pharmacovigilance among the postgraduate and undergraduate medical students in a tertiary care hospital in Central India. Int J Basic Clin Pharmacol. 2017 Apr 24;6(5):1127-32. 
12. Upadhyaya P, Seth V, Moghe VV, Sharma M, Ahmed $\mathrm{M}$. Knowledge of adverse drug reaction reporting in first year postgraduate doctors in a medical college. Therapeutics Clin Risk Management. 2012;8:307.

13. Remesh A. Identifying the reasons for under reporting of ADR: a cross sectional survey. Res J Pharm Biol Chem Sci. 2012;3(4):1379-86.

14. Khan SA, Goyal C, Chandel N, Rafi M. Knowledge, attitudes, and practice of doctors to adverse drug reaction reporting in a teaching hospital in India: An observational study. J Natural Sci Biol Med. 2013 Jan;4(1):191.

15. Gupta P, Udupa A. Adverse drug reaction reporting and pharmacovigilance: Knowledge, attitudes and perceptions amongst resident doctors. J Pharmaceut Sci Res. 2011 Feb 1;3(2):1064.

16. Desai CK, Iyer G, Panchal J, Shah S, Dikshit RK. An evaluation of knowledge, attitude, and practice of adverse drug reaction reporting among prescribers at a tertiary care hospital. Perspect Clin Res. 2011 Oct;2(4):129.

17. Chandrakapure AR, Giri SP, Khan IN, Mohammed M, Mohammed F. Pharmacovigilance: a study to evaluate knowledge, attitude, and practices of and impact of educational intervention among doctors in teaching hospital, in rural area of Jalna, India. Int J Basic Clin Pharmacol. 2017 Jan 18;4(3):427-31.

18. Lopez-Gonzalez E, Herdeiro MT, Figueiras A. Determinants of under-reporting of adverse drug reactions. Drug Safety. 2009 Jan 1;32(1):19-31.

19. Muraraiah S, Rajarathna K, Sreedhar D, Basavalingu D, Jayanthi CR. A questionnaire study to assess the knowledge, attitude and practice of Pharmacovigilance in a paediatric tertiary care centre. J Chem Pharm Res. 2011;3(6):416-22.

20. Tandon VR, Mahajan V, Khajuria V, Gillani Z. Under-reporting of adverse drug reactions: $A$ challenge for pharmacovigilance in India. Indian $\mathrm{J}$ Pharmacol. 2015 Jan;47(1):65.

Cite this article as: Gupta S, Khajuria K, Khajuria $\mathrm{V}$, Kumar N. A questionnaire based study to evaluate the knowledge, attitude and perception towards pharmacovigilance among doctors in rural hospital, Jammu, India. Int J Basic Clin Pharmacol 2018;7:2247-53. 


\section{Annexure 1: Pharmacovigilance questionnaire.}

Profession:

Age:

Sex:

Please tick on the most appropriate option

1. Define Pharmacovigilance.

a) The science detecting the type and incidence of ADR after drug is marketed

b) The science of monitoring ADR's occurring in a Hospital

c) The process of improving the safety of the drug

d) The detection, assessment, understanding and prevention of adverse effects

2. The most important purpose of Pharmacovigilance is

a) To identify safety of the drug

b) To calculate incidence of ADRs

c) To identify predisposing factors to ADR's

d) To identify previously unrecognized ADR's

3. Do you think ADR reporting is professional obligation for you?

a) Yes

b) No

4. The healthcare professionals responsible for reporting ADRs in a hospital is/are

a) Doctor

b) Nurses

c) Pharmacist

d) All of the above

5. Do you know regarding the existence of a National Pharmacovigilance Programme in India?

a) Yes

b) $\quad$ No

6. In India which regulatory body is responsible for monitoring ADRs?

a) Central Drugs Standard Control Organization (CDSCO)

b) Indian Council of Medical Research (ICMR)

c) Indian Clinical Research Institute (ICRI)

d) Medical Council of India (MCI)

7. Where the international center for adverse drug reaction monitoring is located?

a) Unites States of America

b) United Kingdom

c) France

d) Sweden

8. Do you think reporting of adverse drug reaction is necessary?

a) Yes

b) No

9. Do you think Pharmacovigilance should be taught in detail to healthcare professionals?

a) Yes

b) No

10. Have you anytime read any article on prevention of adverse drug reactions?

a) Yes

b) No

11. What is your opinion about establishing ADR monitoring centre in every hospital?

a) Should be in every hospital

b) Not necessary in every hospital

c) One in a city is sufficient

d) Depends on number of bed size in the hospitals

12. Have you ever experienced adverse drug reactions in your patient during your professional practice?

a) Yes

b) No

13. Have you ever reported ADR to the Pharmacovigilance centre?

a) Yes

b) $\quad \mathrm{No}$

14. Have you ever seen the ADR reporting form?

a) Yes 


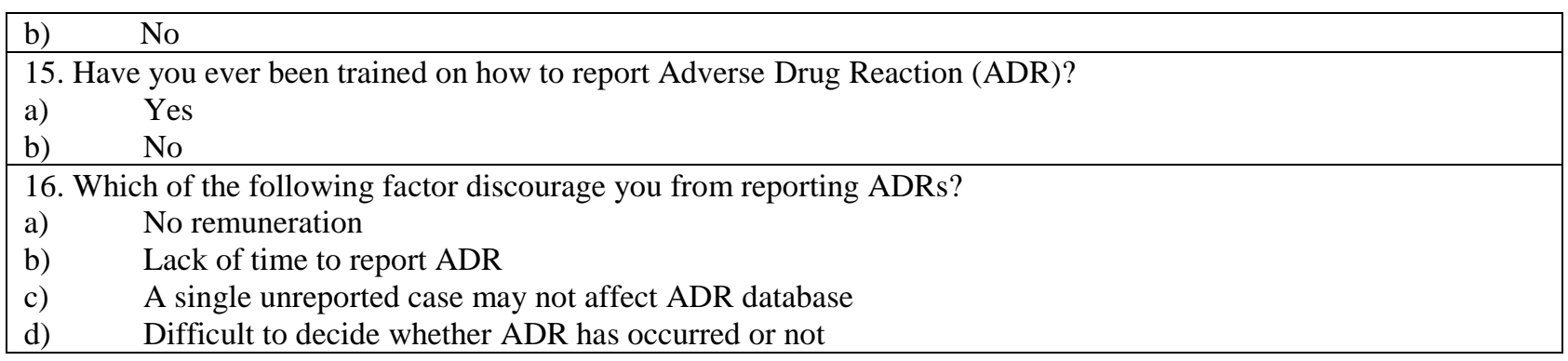

